\title{
Transformation of legal regulation of labor in digital society
}

\author{
Anastasia Alexandrovna Guryeva * \\ Admiral Ushakov Maritime State University, Russia
}

\begin{abstract}
The paper is devoted to the study of the transformation of legal regulation of labor in a digital society. In a comparative legal manner the paper attempts to indicate changes in labor and social security laws, which are also associated with digitalization processes. The influence of digital technologies on modern society is constantly growing: the economy, the sphere of communications between people, culture, life are changing under the influence of artificial intelligence technologies, the Internet of things, digital twins and many others. The digital economy is changing the content of labor relations from the inside through automation and an increasing degree of production robotization. Robotics and complex computer programs transfer some of the functions that employees previously performed, and the share of artificial intelligence systems in the production and service sector is growing rapidly. The algorithms underlying digitalization "penetrate" into legal regulation thus expanding its tools. On the one hand, employees and employers experience the influence of algorithmization through a change in the production environment; on the other hand, processes of law transformation begin in order to adapt legal regulation to the conditions of a digital society to maintain its effectiveness as a social regulator. Based on the results of the study, it is possible to draw conclusions on the objective need for the use of digital instruments by law, which should take into account the level of technology achieved, the existence of a tendency to law algorithmization, and the prerequisites for the further dissemination of algorithms in the field of labor and its legal regulation.
\end{abstract}

\section{Introduction}

The relevance of this topic is dictated by the fact that modern society has entered the era of digital transformation characterized by the rapid development of digital technologies, their mutual strengthening and the introduction of development results into production, services and agriculture in the form of robots supplemented by artificial intelligence and capable of self-improvement, in the form of neurogadgets that make it possible to "read" human brain data and transfer them to artificial intelligence systems for analysis in the form of the Internet of things capable of interacting with each other without human participation, etc.

Digital technologies are unevenly distributed around the world, but, as practice shows, even countries not belonging to world technology leaders quickly perceive the best practices and try to spread them on their territory thus favoring the digital transformation of the economy. Such changes affect the state of employees, the capabilities of employers and require a response from the law. Ideally, labor law needs to "lead" the digital revolution in the labor sphere in order to "win" and achieve the goals of legal regulation - to ensure favorable working conditions, as well as to protect the rights and interests of workers as a "weak" side of labor relations [13]
In the labor market, the share of people performing work not under labor contracts, but on the basis of online platforms - new forms of non-standard employment - is growing.

Thus, the digital future comes, the speed of technology development increases and changes increase, they affect both the economic and political, social, cultural components of society. All this allows talking about the entry of society into an era of digital transformation, which requires an appropriate response from the law.

\section{Problem Statement}

The prerequisites for updating the institute of labor in the conditions of digitalization were, first of all, the factors of economic development - the actual and widespread emergence of relations that allow more efficient entrepreneurial activity with the involvement of employees exercising their labor function outside the employer's location. This global trend was fully reflected in the domestic economy and was supported by the Russian legislator.

The second prerequisite for the renewal of the institute of labor in a digital society was the development of technological conditions for its wide distribution deep digitalization of society, deployment of an extensive network of modern telecommunications 
facilities and provision of a real possibility of its use by end users of a digital product.

The modern institution of legal regulation of labor has become the response of society and the legislator to the challenges of the new economic structure, within the framework of which the emphasis has shifted to the production of intangible goods and services.

For example, the development of legislation on remote labor in the context of its economic need, but without the technological support of society would only be a simulation of the legal regulation of the relevant group of social relations, which are not able to spread widely [11].

Another prerequisite for updating the institute associated with the previous two is the adoption and widespread testing of legislation that allows remotely registering the emergence, change and termination of labor relations, keeping labor books, registering the periods of temporary disability and submission of information on retirement service to the bodies of the Pension Fund of Russia, etc.

Not only was the introduction of new norms preceded by a long experiment involving a wide range of employers, including the largest, the implementation of which becomes the norm for the Ministry of Labor of Russia and can only be welcomed, the practice of applying existing labor standards in digitalization conditions has already become the subject of generalization and analysis [7].

The conditions, under which the current labor legislation has been updated, are the following.

First, the constitution of social partnership in the field of labor and the intensification of the application of its principles and mechanism in the practice of normsetting, increasingly careful accounting of the opinions of the representatives of employees and employers in the Russian tripartite commission for the regulation of social and labor relations when adopting regulatory acts affecting labor relations, the Government of the Russian Federation.

Constitutional reform for the first time in Russian history led to the consolidation of the concept of social partnership at the level of the Basic Law.

The Government of the Russian Federation and the Ministry of Labor in a combination of the impact of the pandemic, digitalization and constitutional reform acted in the spirit of social and labor partnership as bipartism [12].

Thus, the improvement of legislation took place in the context of the self-isolation regime caused by the coronavirus pandemic; forced digitalization of public relations; constitutionalization of social partnership in the field of labor and strengthening of its principles and mechanism in the practice of rulemaking.

The reasons for the emergence of new labor relations were as follows: insufficient regulatory and legal provision; dynamically changing external environment; change of technological structure; emergence of nonstandard forms of employment and growing informal employment; short life cycle of the created professional competences and loss of jobs due to COVID-19 pandemic. The development of the gig economy contributes to the development of the freelance market, and in turn it affects the development of non-standard forms of employment in the labor market.

\section{Materials and Methods}

As prerequisites for the modernization of legal regulation of labor, factors for the development of the economy are identified - actual and widespread emergence of relevant public relations; development of technological conditions for the wide use of labor; adoption and wide-ranging testing of legislation allowing for the formation, change and termination of labor relations in the conditions of digitalization of society.

The improvement of legislation took place in the context of the self-isolation regime caused by the coronavirus pandemic; forced digitalization of public relations; constitutionalization of social partnership in the field of labor and strengthening of its principles and mechanism in the practice of rulemaking.

Among the prospects for legal regulation of labor in a digital society, its extension to all categories of precariates is indicated.

The study made it possible to distinguish and characterize the prerequisites, conditions and prospects for the latest modernization of legal regulation of labor in Russia in the conditions of digitalization, which in itself allows making important clarifications and additions to the existing scientific ideas about the genesis of this institute of labor law and labor legislation.

The study aims to determine and identify certain basic elements - prerequisites, conditions and prospects that could form the basis of a comprehensive theoretical study of the legal regulation of the latest modernization of legal regulation and the use of labor in digital society.

The purpose of the study is to analyze the ongoing socio-economic changes, identify key indicators of these changes and formulate proposals that contribute to the adaptation of labor law to the conditions of digital society.

To achieve this purpose, the processes taking place in society in connection with the development of digital technologies were studied, the impact of these processes on the labor sphere was demonstrated, new legal structures were considered, trends in the development of legal regulation of labor were outlined.

Research methods: comparative legal method, methods of analysis and synthesis, functional and systemic approaches, as well as formal legal method, methods of legal modeling and legal forecasting.

Among the techniques of the study, the general foundations of formal logic (analysis, synthesis, comparison, etc.) and scientific research are used. The formulated proposals and decisions are justified, reasoned and evaluated taking into account the provisions and results achieved by the science of labor law.

There have been structural changes in the labor sphere under the influence of digitalization of the economy, major transformations that labor law needs to comply with changes in the production environment and 
intellectual automation of processes. Given the fact that legal norms have begun to be introduced into the national legislation of most countries, including Russia, to stimulate the strengthening of digitalization of society, it is critical for labor law to monitor and respond to changes in a timely manner. At the same time, it is crucial to ensure consistency in the formation of the image of the future in labor law.

\section{Results and Discussion}

Law, society, and the economy have gone a long way in development, and at each stage changes could be both discontinuous, event-driven or evolutionary. Preindustrial, traditional (agrarian) society was characterized by a natural, agricultural style of the economy; industrial society, the onset of which was due to technological progress, rested upon a developed industrial basis.

It is obvious that digital society and the digital economy are not only more active use of computer technologies and robots in all spheres of life.

We agree with the thesis expressed by A.K. Solovyov that "digitalization of the economy radically changes the entire system of industrial and economic relations in the labor market between its participants employees and employers" [8]. There are deeper changes - digital technologies directly affect the ability of economically active people to work and thus provide for their livelihood, employment, unemployment and, as a result, the fundamental need for social protection and its quantitative and qualitative characteristics. Therefore, today we are actualizing not only the issue of identifying the advantages of digital development, but also a critical understanding of their ability to meet the socio-economic challenges and problems of modern time.

Changing the type of society and economy forces a change in approaches to the legal regulation of labor relations, since the development of information technologies and systems has led to a change in the place and role of a person in the production process. This entails a certain transformation of social security relations. On the one hand, some social risks can develop to a lesser extent, for example, the level of industrial injuries and the number of occupational diseases. On the other hand, changes in the structure of employment lead to an increase in social risks due to instability in the labor market. This affects the change in the volume and content of the needs of the participants in the relevant social relations, as well as the ways in which they are met [4].

According to the Decree of the President of the Russian Federation No. 203 of May 9, 2017 Russia adopted the Strategy for the Development of the Information Society for 2017-2030[2], implying the development of the use of information and communication technologies aimed at ensuring national interests and the implementation of strategic national priorities, improving the quality of life of citizens, increasing labor productivity and production efficiency, and stimulating economic growth to ensure the sustainable and balanced development of our state.

Such a large-scale process, which is based on digitalization, cannot but be accompanied by transformations affecting all spheres of life of society economy, legal and political institutions, social life. These changes are reflected in existing legislation.

It becomes obvious that there is a need to adjust regulatory legal acts of different sectoral affiliation, the purpose of which (in relation to the scope of this study) is to ensure adequate legal regulation of developing public relations for the introduction and use of digital technologies in the process of implementing labor and other directly related relations.

The spread of the new coronavirus infection, which the World Health Organization has categorically described as a pandemic, has affected not only the way of life of people in most countries of the world, but also the organization of the labor process. The subjective assessment of people's life situations has also changed their needs for work, in obtaining educational services, in protecting health, including medical care, in social security, etc.

The issues of legal regulation of the work of distant (remote) workers are also in the spotlight. So, back in 2013, chapter 49.1 appeared in the Labor Code of the Russian Federation dedicated to the peculiarities of labor regulation of remote workers [1]. Remote labor and its active use became possible due to the intensive development of digital technologies. However, it should be noted that in the process of law enforcement practice, the lack of necessary flexibility in legal norms was very quickly revealed, especially in the matter of the partial performance of the employee's work duties remotely.

Moreover, in the context of the spread of a new coronavirus infection, the lack of legal regulation of the work of remote workers that adequately meets the challenges of time has become even more noticeable.

In June 2020, Bill No. 973264-7 “On Amendments to the Labor Code of the Russian Federation regarding the Regulation of Distant and Remote Work" was submitted to the State Duma of the Russian Federation [3]. In its Official Review No. 6031p-P12 of July 15, 2020 the Government of the Russian Federation noted that the proposed changes will contribute to the development of the labor market, increase employment and reduce unemployment among citizens who do not have high competitiveness in this area - disabled people, young people looking for work for the first time, women with young children, people of pre-retirement age, as well as expand the use of flexible forms of employment.

In the first reading, the bill was adopted on July 21, 2020 with the need to submit amendments by September 18, 2020. As of the end of October 2020, this process, unfortunately, has not received its logical completion. At the same time, the need for relevant legal regulation of the work of remote workers has increased again, especially against the background of new restrictive measures taken to prevent a repeated deterioration of the epidemiological situation in the country. 
This bill provides for the possibility of temporary transfer to distant (remote) work due to emergency circumstances.

Unfortunately, the Draft Federal Law No. 973264-7 "On Amendments to the Labor Code of the Russian Federation regarding the Regulation of Distant and Remote Work" [7] does not provide for important changes in the above direction. This act does not fully take into account the interests of the state, business and the population (employees), who need reasonable and fair coordination. In formulating the definition of concepts, the authors of the draft initially admit errors that will later raise logical questions.

For example, temporary distant (remote) work, which means a work regime that provides for the temporary performance of the labor function of an employee working on the basis of an employment contract, outside a stationary workplace under the control of the employer, may include work on a business trip. However, the changes formulated in the draft law do not eliminate the main problems identified during the application of labor legislation in the context of the pandemic, and do not provide adequate protection for businesses and employees in the event of a repetition of such phenomena.

Proposals aimed at reforming certain provisions of the Labor Code of the Russian Federation are fragmentary. They do not solve the main task that the Russian state faces, the achievement of which requires an integrated approach in the analysis, research and decision-making in the field of economics, finance, software and hardware in terms of the introduction of digitalization tools.

The lack of an integrated approach would not allow for an effective legal framework. Any legal means not provided with adequate financial resources, means to ensure the existence and development of economic relations with which the construction of labor relations and those directly related to labor relations is based will not be effective.

In this sense, before making any changes to the Labor Code of the Russian Federation and regulatory legal acts, it is necessary to conduct a serious audit of the current labor legislation and its modern practice, to study the modern economic component and the financial and technical security of their existence and development.

It is necessary in the near future to develop a balanced policy for the development and reform of labor legislation, its main directions, based on a comprehensive and comprehensive analysis of the problems identified in the pandemic, in the interests of the parties to social partnership and in order to harmonize the interests of business and workers, the state and society as a whole [9].

It should be noted that the new national security strategy of Russia approved by Decree of the President of the Russian Federation No. 400 "On the National Security Strategy of the Russian Federation" of July 2, 2021 includes provisions on the use of artificial intelligence technologies in order to increase labor productivity (subparagraph 6, paragraph 67 of the section "Economic security"), artificial intelligence and robotics are identified as priority technologies, the development of which is necessary for the scientific and technological development of Russia (subparagraph 14, paragraph 76 of the section "Scientific and technical development").

The development of digital technologies is pushing the legislator to create rules of law aimed at regulating new or strongly changing relations.

Labor relations are also undergoing significant changes:

1) due to the increasing use of digital means of monitoring the performance of employees' labor duties by employers;

2) increasing level of production automation due to the use of robots and complex computer programs with elements of artificial intelligence to solve tasks that were previously performed by employees;

3) propagation of algorithmic control when artificial intelligence systems control production processes;

4) increase in the proportion of persons performing work based on access to online platforms [9].

Legal scholars - specialists in the field of labor law drew attention to problems in the field of labor that are growing with the introduction of digital technologies.

One of the European researchers studying this topic is Professor M. Gruber-Risak. In his articles he assesses the ongoing processes of introducing technologies into production as threatening workers with a significant deterioration of their situation and insists on the need for a response from labor law to avoid this [17].

Professor J. Adams-Prassl of Oxford in his research deals with social risks growing in the context of digitalization of the economy, and, like M. GruberRisak, points to the need to address a number of important issues by the law [14].

Professor V. de Stefano is another European author who studies the impact of digital technologies on work and changes in the need to regulate legal relations associated with labor. In his articles he insists on the need to take into account the speed of the spread of artificial intelligence technologies in the field of labor when creating and applying law, and also notes the threat posed by the use of gadgets based on neurotechnologies in the labor process demanding a strict restriction on this.

His colleague at Leuven Catholic University, Professor F. Hendricks, believes that due to the digital transformation entailing a reduction in privacy, it is extremely important to formulate more stringent requirements for protecting information about an employee in the law.

Thus, both economists and lawyers from the world's leading research centers insist on the need to pay close attention to the growing wave of labor changes that threaten the well-being of workers [5].

What can and should ensure employment rights in such a situation?

First, to prevent intrusive monitoring of employees using digital technologies and strictly limit the ability of the employer to use neurogadgets that "read" the emotions and thoughts of employees.

Second, to prescribe requirements for the safety of workplaces, the work of which includes close contact 
with robots endowed with artificial intelligence and capable of self-training; provide quotas for jobs as a measure to protect workers from being displaced by robots and decide whether employers' preference for robotics is legitimate as workers over others.

Third, to guarantee employees training that increases their level of proficiency in the digital skills necessary to continue working.

In any case, many workers will lose their usual jobs and will be forced to join the ranks of the self-employed, so the decision to include the self-employed in the scope of labor legislation is inevitable [6].

Thus, resolving the above issues by labor law will make the transition to a digital future less painful for workers, but is not enough to eliminate all the risks associated with the digitalization of the economy and society as a whole.

\section{Conclusion}

The impact of digitalization on labor relations has become obvious, so research in this direction has acquired an interdisciplinary nature at the intersection of economics, management, jurisprudence and information technology.

Managing transformation at work through law is a prerequisite for the well-being of human society. Labor legislation, on the one hand, must be flexible enough to respond to economic and technological changes, on the other hand, to remain socially oriented thus ensuring high employment, decent working conditions for all employed persons, as well as the maximum protection for the most vulnerable groups of workers. As we see, it is difficult to achieve this result, and it is impossible to achieve it in isolation from other branches of law, so one of the tasks of specialists in the field of labor law is to expand the horizon of research to obtain a holistic picture of the changes that are taking place and to develop proposals for reforming labor legislation on its basis.

There is no doubt that creating an information society with a digital economy is not a simultaneous process, and it is complex. It is related to both the pace of technological progress and the growth of incomes of the population, which together can provide access to high technology to more people and thus contribute to improving the enjoyment of citizens' rights in the field of work and social security. Besides, it is necessary to increase the level of knowledge of citizens on the information space, digital technologies and systems in order to overcome difficulties and distrust of the upcoming future.

The spread of the new coronavirus infection has led many things to look in a new way, reassess the existing legal measures and outline the ways in which it will develop in the future. According to the International Labor Organization, large-scale transformations taking place in the economy, including under the influence of new technologies, will cause devastating and transformative consequences in the economy and labor.
Despite the fact that the adoption of a bill revising approaches to the legal regulation of remote work has been delayed in our country, some of its provisions may be assessed as progressive, contributing to the development of labor relations. This will preserve labor relations and ensure the necessary level of employment even in emergency situations.

Digital technologies, while volatile, demonstrate the potential to promote the stability of both labor and social security regulations.

\section{References}

1. Labor Code of the Russian Federation No. 197-FZ of 30.12.2001 (edited as of 28.06.2021) (with changes and amendments, came into force on 01.09.2021). Collection of Legislation of the Russian Federation, 07.01.2002, No. 1 (part 1), Art. 3.

2. Decree of the President of the Russian Federation dated 09.05.2017 No. 203 "On the Strategy for the Development of the Information Society in the Russian Federation for 2017-2030”. Collection of Legislation of the Russian Federation, 15.05.2017, No. 20, Art. 2901.

3. Draft federal law No. 973264-7 "On the introduction of amendments to the Labor Code of the Russian Federation regarding regulation of distant (remote) work and temporary transfer of the worker for distant (remote) work on an initiative of the employer in exceptional cases" (final edition accepted by the State Duma of Federal Assembly of the Russian Federation 26.11.2020). Text of the document is cited according to the publication on the website https://sozd.duma.gov.ru/ as of 25.11.2020.

4. S.H. Dzhioev, To the question of the optimal model of labor legal relations in the conditions of digitalization, Gaps in Russian legislation, 13(5), 92-96 (2020)

5. Yu.V. Ivanchina, E.A. Istomina, Digitalization of social and labor relations in a changing world: comparative legal analysis, Bulletin of Tyumen State University. Socio-economic and legal research, 6(4), 192-213 (2020)

6. G.R. Igbaeva, Legal consequences of transformational processes in the sphere of labor in the conditions of digitalization, Eurasian Legal Journal, 7(158), 244245 (2021)

7. A.M. Kunichkin, L.R. Khairulina, Regulation of labor relations in the conditions of digitalization of society, In the collection: Potential of the Russian economy and innovative ways to implement it, $\mathrm{pp}$. 49-52 (2020)

8. A.K. Soloviev, Digital economy is the main challenge to social and labor relations, In the collection: Management of innovative and investment processes for the formation and development of industrial enterprises in the digital economy, pp. 207-213 (2018) 
9. I.A. Filipova, Algorithmization: impact on the labor sphere and its regulation, Russian Justice, 11, 12-14 (2020)

10. I.A. Filipova, Digital future: sphere of labor and the management of its transformation with the help of law, Labor and social law, 3(39), 30-34 (2021)

11. S.Yu. Chucha, Modernization of legal regulation of remote labor in Russia: prerequisites, conditions, prospects, Bulletin of Omsk University. Series: Law, 18(2), 64-73 (2021)

12. S.Yu. Chucha, Features of legal regulation of labor in the conditions of pandemic and digitalization of society, In the collection: For the rights of workers! Protecting the social and labor rights of workers in a changing world: opportunities and restrictions,
Yu.V. Ivanchina, E.A. Istomina (eds.), pp. 173-177 (Yekaterinburg, 2021)

13. V.M. Yachmeneva, E.F. Yachmenev, Formation of labor relations in the digital economy: realities and prospects, Scientific bulletin: finance, banks, investments, 4(53), 87-94 (2020)

14. A.A. Guryeva, Digitalization of the transport complex of the Russian Federation and its role in improving the quality of passenger and cargo transportation. In: Scientific research: yesterday, today, tomorrow: collection of scientific papers of scientists, teachers, students, undergraduates and practitioners: collection of articles (RUSAINS, Moscow, 2021). 204 p. 